\title{
ChemComm
}

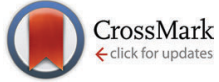

Cite this: Chem. Commun., 2015 51,298

Received 6th September 2014, Accepted 30th October 2014

DOI: $10.1039 / c 4 c c 07049 f$

www.rsc.org/chemcomm

\section{Titania photocatalysis through two-photon band-gap excitation with built-in rhodium redox mediator $\dagger$}

\author{
Joanna Kuncewicz ${ }^{*^{a}}$ and Bunsho Ohtani ${ }^{b}$
}

Titania particles modified with an extremely small amount ( $<0.01 \mathrm{~mol} \%)$ of a rhodium species exhibited photocatalytic activity for the oxidative decomposition of acetaldehyde in air under visible-light irradiation. The reaction proceeded via a two-photon band-gap excitation mechanism resembling the Z-scheme with an external redox couple, using a built-in $\mathrm{Rh}(\mathrm{III})-\mathrm{Rh}$ (Iv) redox couple.

It has been often reported in studies of visible-light-active photocatalysts that titanium(Iv) oxide (titania) has many advantages as a photocatalyst, including chemical stability both in the dark and under photoirradiation, sufficient redox ability in the excited state that can induce water splitting, non-toxicity, and high availability. However, titania can only be excited by UV light. ${ }^{1}$ To overcome this sole disadvantage of titania, there are two strategies. One is to find a photocatalyst that absorbs visible light with the advantages of titania, although such a "superman" metal-oxide photocatalyst has not yet been discovered despite 40 years of research. Another strategy is to modify titania to give visible-light absorption by doping with nitrogen, ${ }^{2}$ sulfur $^{3}$ or carbon, ${ }^{4}$ or by loading metal oxide clusters ${ }^{5}$ to obtain filled and vacant electronic states, respectively, in the band gap of titania. However, the redox ability of titania may be lost, because in these strategies, positive holes in the valence band (VB) and photoexcited electrons in the conduction band $(\mathrm{CB})$ of titania, which induce redox reactions when titania is excited by UV light, cannot be used. Therefore, a further strategy for developing visible-light-active titania is to introduce a mechanism of two-photon band-gap excitation.

\footnotetext{
${ }^{a}$ Faculty of Chemistry, Jagiellonian University, ul. R. Ingardena 3, 30-011 Kraków, Poland. E-mail: kuncewic@chemia.uj.edu.pl; Fax: +48 126340515; Tel: +48126632005

${ }^{b}$ Catalysis Research Center, Hokkaido University, Sapporo 001-0021, Japan. E-mail: ohtani@cat.hokudai.ac.jp; Fax: +81 11706 9133; Tel: +81 117069132 $\dagger$ Electronic supplementary information (ESI) available: Preparation procedure and experimental details, XRD patterns of $\mathrm{Rh}-\mathrm{TiO}_{2}$ samples, example of the timecourse curve of photocatalytic test reaction, dependency of photocatalytic reaction rate on Rh-concentration determined for the materials calcined at $973 \mathrm{~K}$, differential absorption spectra recorded for $0.01 \% \mathrm{Rh}-\mathrm{TiO}_{2}$ kept in a dark in the presence of AcH and irradiated. See DOI: 10.1039/c4cc07049f
}

Rhodium (Rh)-doping, where base material is modified with a small amount of a Rh species without changing the original crystal structure, has been used to develop visible-light-active titania $^{6-9}$ or strontium titanate $\left(\mathrm{SrTiO}_{3}\right) .{ }^{10-14}$ It was proposed that photoexcitation from $\mathrm{Rh}(\mathrm{III})$ to the $\mathrm{CB}$ of titania or $\mathrm{SrTiO}_{3}$ leaves Rh(Iv), which oxidizes compounds adsorbed on the surface. Thus, although the CB electrons can be used in a reduction step, as in UV band-gap excitation, oxidation is induced by a localized species, Rh(Iv), not by VB positive holes. Here we report the visible-light-induced photocatalysis by titania modified with an extremely small amount of $\mathrm{Rh}$, in which both VB holes and CB electrons participate through two-photon bandgap excitation.

In the present work, Rh-modified titania $\left(\mathrm{Rh}-\mathrm{TiO}_{2}\right)$ samples were prepared by impregnating commercial titania (anatase; Showa Denko Ceramics FP6) with rhodium(III) chloride $\left(\mathrm{RhCl}_{3}\right.$; Wako Pure Chemical; 0.001-0.1 mol\%) followed by calcination in air at $923 \mathrm{~K}$ for $3 \mathrm{~h}$ to produce rutile materials, as confirmed by X-ray diffractometry ( $\mathrm{ESI} \dagger)$. A reference sample $\left(0 \% \mathrm{Rh}-\mathrm{TiO}_{2}\right.$; rutile) was prepared by a similar calcination process without adding $\mathrm{RhCl}_{3}$. Representative photoabsorption spectra are shown in Fig. 1. In addition to the absorption at $<420 \mathrm{~nm}$ by rutile titania, two shoulders were present at 450 and $620 \mathrm{~nm}$

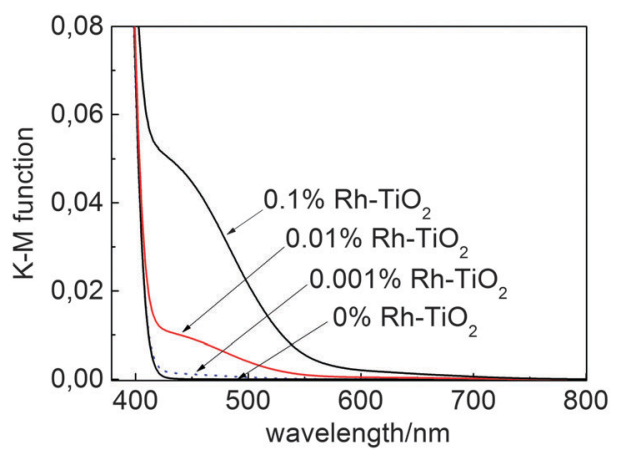

Fig. 1 Diffuse reflectance spectra of $\mathrm{Rh}-\mathrm{TiO}_{2}$ and a reference sample without rhodium species. 


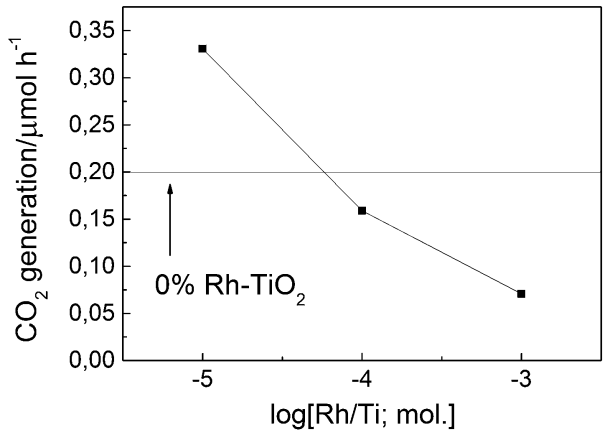

Fig. 2 Rates of $\mathrm{CO}_{2}$ liberation during the first $2 \mathrm{~h}$ of the oxidative decomposition of acetaldehyde in the presence of materials with various $\mathrm{Rh}$ concentrations (black line $-\mathrm{CO}_{2}$ generation rate in the presence of bare titania).

that were attributed to $\mathrm{Rh}(\mathrm{III})$ and $\mathrm{Rh}(\mathrm{IV})$, respectively, ${ }^{7,15}$ after Rh-modification. A peak at $620 \mathrm{~nm}$ was evident for the sample with a relatively large amount of $\mathrm{Rh}(>0.01 \%)$, what indicated that in studied samples loaded Rh was mainly $\mathrm{Rh}(\mathrm{III})$.

The photocatalytic activity of samples was evaluated by the rate of carbon dioxide $\left(\mathrm{CO}_{2}\right)$ liberation by visible-light photoirradiation $(>440 \mathrm{~nm})$ of a sample $(50 \mathrm{mg})$ in a $1 \mathrm{~cm}^{2}$ sample holder placed in a reaction chamber $(357 \mathrm{~mL})$ containing air and $224 \mathrm{ppm}$ of acetaldehyde (AcH). As Fig. 2 shows, activity higher than that of bare $\mathrm{TiO}_{2}$ was observed for the sample modified with an extremely small amount of $\mathrm{Rh}(<0.01 \%)$. The origin of the visible-light activity of bare $\mathrm{TiO}_{2}$ may be a very small undetectable absorption arising from surface states and is still ambiguous; however, the dependence of the activity on the loading suggests that the $\mathrm{TiO}_{2}$ activity might be diminished by overlaying a larger amount of Rh species, which hinders the intrinsic photoabsorption of titania. A possible reason for the lower photocatalytic activity of samples with a larger amount of $\mathrm{Rh}$ may also be the higher content of $\mathrm{Rh}(\mathrm{Iv})$, which was negligible for samples with an extremely low Rh loading (Fig. 1), which may act as an electron trap that enhances electron-hole recombination. $^{7,12}$ Thus, an extremely small amount of Rh gives titania visible-light activity. The optimal $\mathrm{Rh}$ concentration should be around $0.0005-0.001 \%$, which was also confirmed by studies of the photocatalytic activity of less active samples calcined at a slightly higher temperature (973 K) (ESI $\dagger$ ). Characterization of the sample with $\mathrm{Rh}$ at such low concentrations was difficult because of the small intensity of the photoabsorption of the Rh species. Therefore, a $0.01 \%$ sample was used for the following experiments. The active Rh species were probably small particles attached to the surface because repeated rinsing of the samples with water caused appreciable, but not complete, loss of the photoabsorption and almost complete loss of the photocatalytic activity under visible-light irradiation. Because of the extremely small amount of Rh atoms (0.008-0.08) per $1 \mathrm{~nm}^{2}$ of titania with a specific surface area of $10 \mathrm{~m}^{2} \mathrm{~g}^{-1}$, isolated $\mathrm{Rh}$ ions may be dispersed on the titania surface in the form of oxide clusters. They may even be embedded in the titania crystal lattice near the surface, which is supported by the observed strong interaction of the $\mathrm{Rh}$ species with titania.

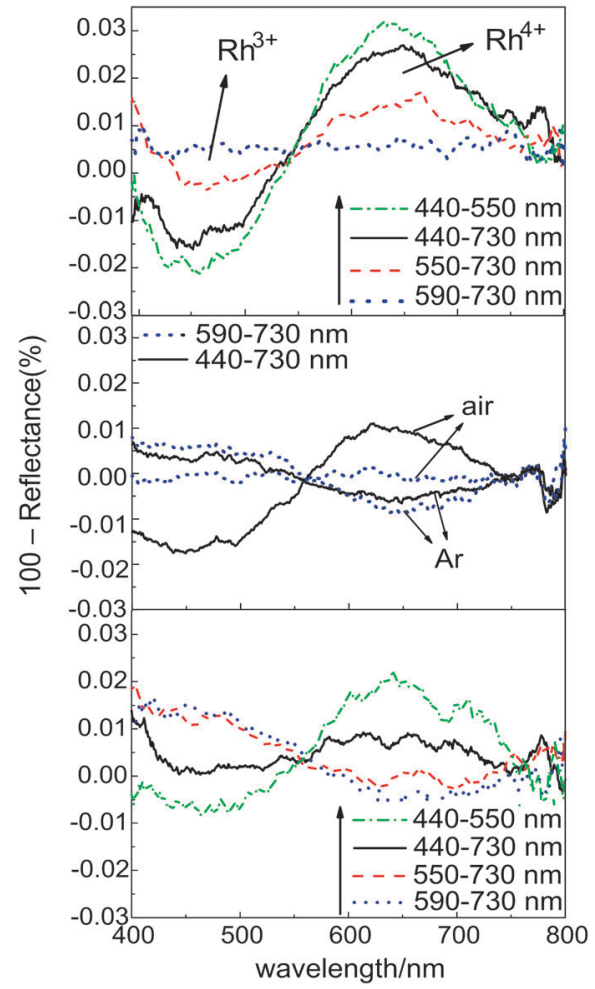

Fig. 3 Differential absorption spectra of $0.01 \% \mathrm{Rh}-\mathrm{TiO}_{2}$ (with reference to the spectrum of the sample kept in a dark) under photoirradiation with light of various wavelength ranges (upper) in air, (middle) in air or under argon, and (lower) in the presence of $\mathrm{AcH}$ in air.

It should be noted that the photoabsorption of the active samples changed during the photoirradiation and the behavior depended on the photoirradiation wavelength range. Upon irradiation with light in the wavelength range of $440-550 \mathrm{~nm}$, which overlapped the absorption band assigned to $\mathrm{Rh}(\mathrm{III})$, decrease in the intensity of that band was observed whereas the intensity of the band assigned to $\mathrm{Rh}(\mathrm{Iv})$ increased. Subsequent irradiation with full wavelength range light $(440-730 \mathrm{~nm})$ caused a slight increase in the intensity of the $450 \mathrm{~nm}$ band and a decrease in the $620 \mathrm{~nm}$ band, respectively; the longer wavelength irradiation $(550-730 \mathrm{~nm})$ recovered $\mathrm{Rh}(\mathrm{III})$ from the $\mathrm{Rh}$ (Iv) (Fig. 3, upper panel). Irradiation with longer wavelength light $(590-730 \mathrm{~nm})$ recovered $\mathrm{Rh}(\mathrm{III})$ to the original concentration, because the transition of $\mathrm{Rh}(\mathrm{III})$ to $\mathrm{Rh}(\mathrm{IV})$ cannot be induced by this longer-wavelength irradiation. Photoinduced regeneration of $\mathrm{Rh}$ (III) under the irradiation with light from the range $590-730 \mathrm{~nm}$, appeared to be slower than the reverse process. The in situ photoabsorption measurements shown in Fig. 3 (lower panel) confirmed the light wavelength-controlled reversibility of these redox processes during the photocatalytic reactions.

The photoinduced absorption changes depended strongly on the presence or absence of electron acceptors and donors in the system (Fig. 3). In the absence of oxygen, the photoinduced generation of $\mathrm{Rh}$ (Iv) was not observed or the original $\mathrm{Rh}(\mathrm{Iv})$ concentration decreased upon irradiation. This indicated that shorter wavelength light does not work, because electrons 


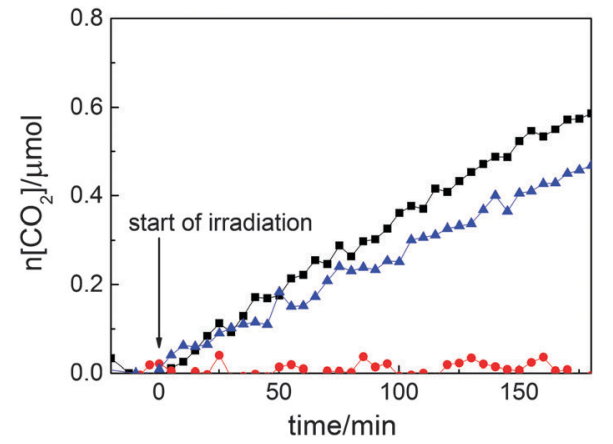

Fig. 4 Amounts of $\mathrm{CO}_{2}$ generated during $\mathrm{AcH}$ oxidative decomposition in the presence of $0.01 \% \mathrm{Rh}-\mathrm{TiO}_{2}$ under irradiation with various light ranges ([440-550 nm and 590-730 nm] - black squares, [440-550 nm] - blue triangles, [590-730 $\mathrm{nm}$ ] - red circles).

excited from $\mathrm{Rh}(\mathrm{III})$ to the titania $\mathrm{CB}$ must be consumed by oxygen adsorbed on the surface. In contrast, the presence of AcH enhanced photoinduced regeneration of $\mathrm{Rh}(\mathrm{III})$; higher and lower concentrations of $\mathrm{Rh}(\mathrm{III})$ and $\mathrm{Rh}(\mathrm{IV})$, respectively, were observed for all wavelength ranges. This suggested that the efficiency of the photoinduced reduction of $\mathrm{Rh}$ (Iv) may be improved by increasing the consumption of the VB positive holes by $\mathrm{AcH}$. The $\mathrm{Rh}(\mathrm{Iv}) / \mathrm{Rh}$ (III) ratio also decreased slowly in the dark in the presence of $\mathrm{AcH}$, indicating that $\mathrm{AcH}$ reduces $\mathrm{Rh}$ (Iv) slowly (ESI $\dagger$ ).

Thus, $\mathrm{Rh}-\mathrm{TiO}_{2}$ photocatalysis contains at least two independent photoexcitation processes: excitations from $\mathrm{Rh}$ (III) to the titania CB by $440-550 \mathrm{~nm}$ light, and from the titania VB to $\mathrm{Rh}$ (Iv) by irradiation with wavelengths from 590 to $730 \mathrm{~nm}$. To confirm the synergy of these two photoreactions, the experiments shown in Fig. 4 were performed (ESI $\dagger$ ), in which the full output (440-730 nm) of a xenon arc was divided into two wavelength ranges, $440-550 \mathrm{~nm}$ and $590-730 \mathrm{~nm}$ (provided by two light sources ensuring similar radiation intensities (ESI $\dagger$ )), which corresponded to photoabsorption by $\mathrm{Rh}(\mathrm{III})$ and $\mathrm{Rh}(\mathrm{Iv})$, respectively. Negligible photocatalytic activity under the longer wavelength irradiation was attributed to the lower concentration of $\mathrm{Rh}$ (Iv) excited, which could not be generated under these irradiation conditions, and the accumulation of electrons in $\mathrm{Rh}$ (III) without transfer to oxygen. However, the rate of $\mathrm{CO}_{2}$ liberation when irradiated in both wavelength ranges was higher than that under irradiation with shorter wavelength light. The synergetic effect was observed for $0.01 \% \mathrm{Rh}-\mathrm{TiO}_{2}$, whereas no synergetic effect over the full range of irradiation was observed for $0 \% \mathrm{Rh}-\mathrm{TiO}_{2}$. Analysis of the absorption spectra of $0.01 \%$ $\mathrm{Rh}-\mathrm{TiO}_{2}$ recorded during the full-range irradiation in the presence of AcH showed negligible detectable change in the $\mathrm{Rh}(\mathrm{III}) / \mathrm{Rh}(\mathrm{Iv})$ ratio. In contrast, shorter wavelength irradiation caused $\mathrm{Rh}$ (Iv) to accumulate because of the slow reduction by $\mathrm{AcH}$ without photoinduced reduction, which might induce the slow deactivation of the sample under these conditions (Fig. 3, lower panel). A slightly higher increase of the reaction rate upon full-range irradiation observed at the beginning of the reaction might be explained by the recapturing of active $\mathrm{Rh}$ (III) through the reduction of $\mathrm{Rh}$ (Iv) intrinsically present in the sample.

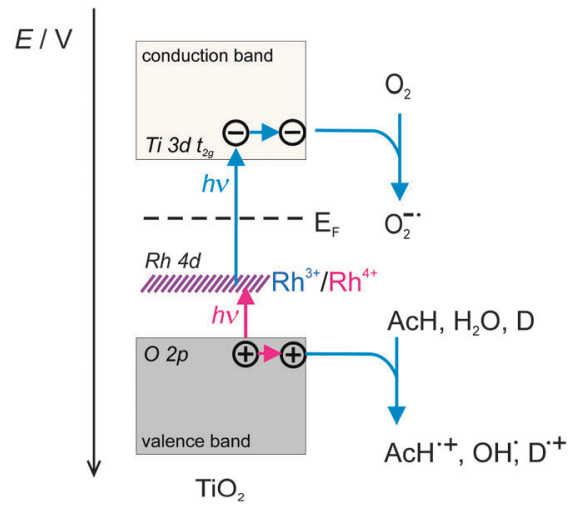

Fig. 5 Schematic representation of the mechanism of the photocatalytic reaction with $\mathrm{Rh}-\mathrm{TiO}_{2}$ ( $\mathrm{D}$ - electron donor).

Based on these results and discussion, a schematic representation of the mechanism of the present photocatalytic reaction system with $\mathrm{Rh}-\mathrm{TiO}_{2}$ is shown in Fig. 5 . Higher energy photons (440-590 nm) excite electrons in $\mathrm{Rh}$ (III) into the titania CB to leave $\mathrm{Rh}(\mathrm{Iv})$, whereas lower energy photons (590-730 nm) excite electrons in the titania $\mathrm{VB}$ to $\mathrm{Rh}$ (Iv) to leave positive holes in the $\mathrm{VB}$ and to recover $\mathrm{Rh}(\mathrm{III})$. As a result, $\mathrm{CB}$ electrons and VB positive holes are generated by two types of visible-light photons, and a two-photon band-gap excitation proceeds using the $\mathrm{Rh}$ species as a built-in redox mediator. This mechanism is supported by theoretical calculations, which showed that Rh-doping of rutile titania should induce intermediate bands within the titania band gap. ${ }^{15-17}$ This photocatalyst has at least three advantages. First, the two different excitation processes occur in each titania particle because of the built-in redox mediator, which is different to Z-scheme photocatalysis using two kinds of photocatalyst particles. ${ }^{18-21}$ Second, the titania maintains a sufficient redox ability because of the bandgap excitation. Third, the two excitations require different ranges of light wavelengths that do not overlap. Because ordinary light sources, such as solar radiation, contain light with a wide range of wavelengths covering both excitation processes in the photocatalyst, the overall efficiency is not decreased even if two photons are required to produce the band-gap excitation.

At present, the overall efficiency is too low to be competitive with rutile titania under visible-light irradiation. This must be improved by increasing the concentration of active Rh species and by avoiding the formation of large aggregates of Rh oxide. This could be achieved by true doping of Rh(Iv) ions in the titania lattice, which should be possible because the ionic radius of $\mathrm{Rh}(\mathrm{rv})$ is similar to that of Ti(Iv) and the valency and coordination of $\mathrm{Rh}(\mathrm{Iv})$ and Ti(Iv) are the same. We are currently investigating this.

The present mechanism of the two-photon band-gap excitation of titania is, as far as we know, the sole possible solution for overcoming the main disadvantage of a titania photocatalyst that is not excited by visible light, without losing the advantages of the catalyst. The mechanism also provides a new insight into visible-light-induced photocatalysis by metal-oxide particles.

This work was supported by the Ministry of Science and Higher Education in Poland within Iuventus Plus grant (No. IP 2012030572). 


\section{References}

1 A. Fujishima, X. Zhang and D. A. Tryk, Surf. Sci. Rep., 2008, 63, 515-582.

2 R. Asahi, T. Morikawa, T. Ohwaki, K. Aoki and Y. Taga, Science, 2001, 293, 269-271.

3 T. Umebayashi, T. Yamaki, H. Itoh and K. Asai, Appl. Phys. Lett., 2002, 81, 454-456.

4 H. Irie, Y. Watanabe and K. Hashimoto, Chem. Lett., 2003, 32, 772-773.

5 Y. Nosaka, S. Takahashi, H. Sakamoto and A. Y. Nosaka, J. Phys. Chem. C, 2011, 115, 21283-21290.

6 W. Choi, A. Termin and M. R. Hoffmann, J. Phys. Chem., 1994, 98, 13669-13679.

7 R. Niishiro, R. Konta, H. Kato, W.-J. Chun, K. Asakura and A. Kudo, J. Phys. Chem. C, 2007, 111, 17420-17426.

8 A. K. P. D. Savio, J. Fletcher and F. C. R. Hernandez, Ceram. Int., 2013, 39, 2753-2765.

9 Y. Matsumoto, T. Shimizu, A. Toyoda and E. Sato, J. Phys. Chem., 1982, 86, 3581.
10 R. Konta, T. Ishii, H. Kato and A. Kudo, J. Phys. Chem. B, 2004, 108, $8992-8995$.

11 K. Iwashina and A. Kudo, J. Am. Chem. Soc., 2011, 133, 13272-13275.

12 K. Furuhashi, Q. Jia, A. Kudo and H. Onishi, J. Phys. Chem. C, 2013, 117, 19101-19106.

13 H. W. Kang and S. B. Park, Int. J. Hydrogen Energy, 2013, 38, 823-831.

14 P. Shen, J. C. Lofaro Jr., W. R. Woerner, M. G. White, D. Su and A. Orlov, Chem. Eng. J., 2013, 223, 200-208.

15 F. E. Oropeza and R. G. Egdell, Chem. Phys. Lett., 2011, 515, 249-253.

16 K. K. Ghuman and C. V. Singh, J. Phys.: Condens. Matter, 2013, 25, 475501.

17 K. Song, X. Han and G. Shao, J. Alloys Compd., 2013, 551, 118-124.

18 Y. Sasaki, H. Nemoto, K. Saito and A. Kudo, J. Phys. Chem. C, 2009, 113, 17536-17542.

19 K. Sayama, K. Mukasa, R. Abe, Y. Abe and H. Arakawa, J. Photochem. Photobiol., A, 2002, 148, 71-77.

20 Y. Sasaki, A. Iwase, H. Kato and A. Kudo, J. Catal., 2008, 259, 133-137.

21 R. Abe, J. Photochem. Photobiol., C, 2010, 11, 179-209. 